\title{
Strong threads and weak chains? - a graph theoretical estimation of the power of indirect effects
}

\author{
F. Jordán
}

Collegium Budapest, Institute for Advanced Study, Budapest, H-1014, Szentháromság u. 2., and Department of Genetics, Eötvös University, Budapest, H-1088, Múzeum krt. 4/a, Hungary; Phone: (36)-1-22-48-326; fax: (36)-1-22-48-310; E-mail: fjordan@colbud.hu

Keywords: Indirect effects, Network perspective, Trophic interactions.

\begin{abstract}
Food webs inform about both direct trophic interactions (predation and food supply) and implicitly involved, indirect ones (e.g. exploitative competition). Traditionally, direct links between species are considered stronger and more important. However, as a body of experimental results suggests, indirect links may well be able to surpass their effects. In this paper, after shortly summarizing an interesting case study, I propose a simple structural approach to estimate the role of indirect vs. direct effects.
\end{abstract}

\section{Introduction}

Predation is frequently considered of primary importance among community control mechanisms (e.g., Margalef 1968), while other interactions (like mutualism) are ranked lower in significance. The important role of competitive interactions has also been acknowledged (e.g. Schoener 1983), sometimes as complementing predation control (Hairston et al. 1960, Menge and Sutherland 1976). But, traditionally, the food web approach (Cohen 1978 , Pimm 1982) is considered probably the best in analysing community control.

However, as the additivity of pairwise interspecific interactions is frequently criticised (Kareiva 1994, Wootton 1994b, and a case study by Morin et al. 1988), studies on indirect effects (Abrams 1983, Billick and Case 1994, Menge 1995, Abrams et al. 1996, Menge 1997, Morin 1999) lead to a very complex view on how communities are organised. But it should be emphasised that food webs are not just simple collections of predatory links but also give much useful information about a number of important indirect effects (e.g., exploitative competition as a logical consequence of two predatory links). Thus, the network perspective of ecology (Higashi and Burns 1991) is far more useful than sometimes thought.

In this comment, in connection with a thrilling case study (Palomares et al. 1995), I suggest a simple graph theoretical model estimating quantitatively the local and global power of indirect effects. This case study gives an excellent example for how an indirect effect (here, a trophic cascade) can be stronger between two species than a direct interaction (predation). Such cases (where "threads" are stronger than "chains", see Power et al. 1996) strongly claim for quantitative studies on indirect control (see also the experimental approach by Wootton 1994a).

\section{The problem}

Rabbit is the main food of Iberian lynx in the Doñana National Park, Spain. Lynx also eats smaller predators (SPs, e.g. mongoose), that are in turn important consumers of rabbit (Figure 1). The combination of the direct feeding links between lynx and SPs, and between SPs and rabbit results in a density-mediated indirect link between lynx and rabbit (a trophic cascade effect, Paine 1980). Thus, between lynx and rabbit there is (1) a direct, positive, bottom-up link (food supply), (2) a direct, negative, top-down link (predation), and (3) an indirect, positive, top-down interaction (trophic cascade). Interestingly, the indirect trophic cascade effect has been shown to be stronger than the predatory interaction, i.e., more lynx means more rabbits, even though the first is a predator of the second (Palomares et al. 1995). This case study is one of the many recent results claiming for quantitative approaches in estimating (or even measuring) the importance of indirect control on population dynamics. Both experimental (see Wootton 1994a) and theoretical (Ulanowicz and Puccia 1990) studies may be helpful. 


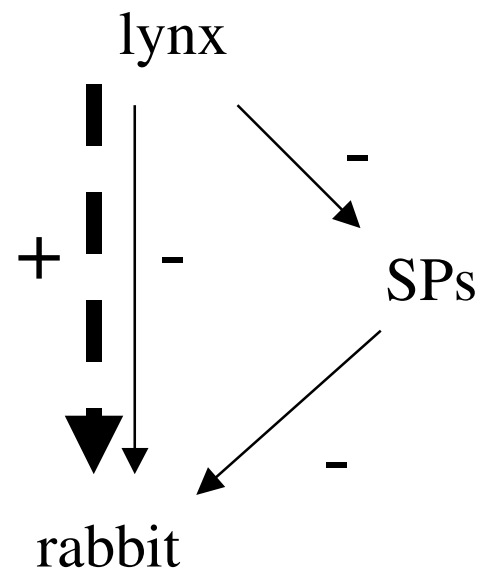

Figure 1. Trophic interactions between lynx, rabbit and smaller predators (SPs, like mongoose) in Doñana National Park, Spain. The food web explicitly involves predatory links (direct, negative link; thin arrows). The trophic cascade effect (indirect, positive links; thick, dotted arrow) is implicitly given in the food web (after Palomares et al. 1995).

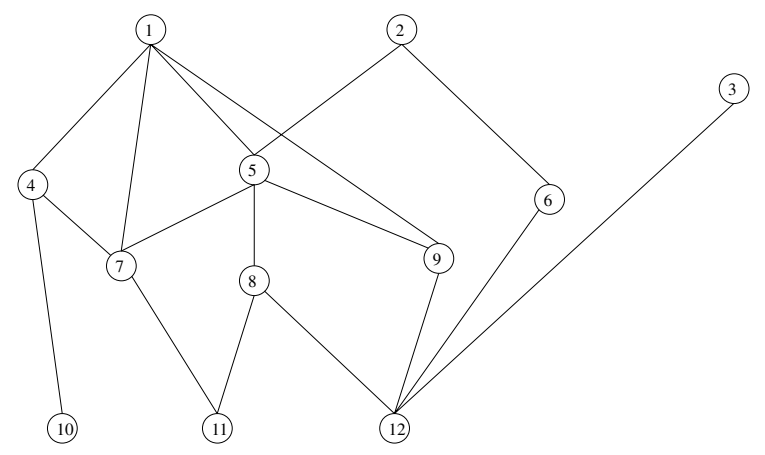

Figure 2. An hypothetical food web containing 12 species and predatory links between them.

If our knowledge from direct, pairwise interactions must be complemented by explicitly studying indirect interactions, food webs may seem to be less useful than we think first. However, the majority of indirect interactions can be predicted from trophic networks (another example is apparent competition, Abrams and Matsuda 1993), while others cannot (indirect mutualism also involves a competitive link not shown in a trophic network, see Abrams et al. 1996). If some top-down control mechanisms are implicit in trophic networks (like the trophic cascade from lynx to rabbit), trophic flow networks could be analysed also in the top-down direction (Jordán et al. 1999, Jordán 2000). In this case, not only nutrients or en- ergy are traced but various kinds of trophically mediated regulatory effects, too (these webs could be named trophic interaction networks, as a combination of interaction webs, sensu Paine 1980, and trophic networks). In the following, I present two graph theoretical indices of trophic interaction networks whose combinations are proposed to estimate the power of indirect effects in community control.

\section{An approach}

The number of points connected to the $x^{\text {th }}$ graph point gives how many direct trophic interactions species $x$ has (degree, $D$ ). These can be either "predation" or "food supply" links, in top-down or bottom-up directions, respectively, given by in-degrees $\left(D_{i n}\right)$ and out-degrees $\left(D_{\text {out }}\right)$, respectively. $D$ characterises locally the direct trophic control ability of species $x$.

A graph theoretical index (status, Harary 1961) has been slightly modified in order to be ecologically more reasonable (keystone index, Jordán et al. 1999). This in$\operatorname{dex}\left(K_{x}\right)$ refers to both direct and indirect effects, by quantifying the positional importance of species $x$ within a network. Here, importance means the number of points disconnected from their sources by deleting species $x$ (recall the dynamical version of this structural approach, Pimm 1980):

$$
K_{x}=\sum_{c=1}^{n} \frac{1}{d_{c}} \cdot\left(1+K_{b c}\right)+\sum_{e=1}^{m} \frac{1}{f_{e}} \cdot\left(1+K_{t e}\right)
$$

where

- $n$ is the number of predators eating species $x$,

$-d_{c}$ is the number of preys of its $c^{t h}$ predator,

- $K_{b c}$ is the $K_{b}$ index of the $c^{t h}$ predator; and symmetrically,

- $m$ is the number of preys eaten by species $x$,

$-f_{e}$ is the number of predators of its $e^{t h}$ prey, and

- $K_{t e}$ is the $K_{t}$ index of the $e^{t h}$ prey.

The network analysis of an hypothetical food web (Figure 2) is presented and the structural indices of "species" are given in Table 1 . Since $D$ and $K$ characterise $d i$ rect and direct plus indirect positional effects, respectively, their certain combinations $(K-D$ and $K / D)$ may estimate the power of indirect control. However, it is hard to predict whether $K-D$ or $K / D$ gives a better measure of the strength of indirect control; their combinations clearly identify some domains containing characteristically different graph points (Figure 3) as follows: (1) open circles: 
Table 1. Simple graph theoretical indices characterising species (referred to as "points") of the food web shown in Fig. 2 (see explanation in text).

\begin{tabular}{lrrrrrr}
\hline & D(in) & D(out) & D & K & K-D & K/D \\
\hline point 1 & 4 & 0 & 4 & 5.56 & 1.56 & 1.39 \\
point 2 & 2 & 0 & 2 & 3.19 & 1.19 & 1.6 \\
point 3 & 1 & 0 & 1 & 0.25 & -0.75 & 0.25 \\
point 4 & 2 & 1 & 3 & 1.75 & -1.25 & 0.58 \\
point 5 & 3 & 2 & 5 & 3.63 & -1.38 & 0.73 \\
point 6 & 1 & 1 & 2 & 0.75 & -1.25 & 0.38 \\
point 7 & 1 & 3 & 4 & 1.96 & -2.04 & 0.49 \\
point 8 & 2 & 1 & 3 & 1.33 & -1.67 & 0.44 \\
point 9 & 1 & 2 & 3 & 1.08 & -1.92 & 0.36 \\
point 10 & 0 & 1 & 1 & 0.63 & -0.38 & 0.63 \\
point 11 & 0 & 2 & 2 & 3.25 & 1.25 & 1.63 \\
point 12 & 0 & 4 & 4 & 5.12 & 1.12 & 1.28 \\
\hline \hline
\end{tabular}

either producers or top-predators with many links; (2) open square: either producers or top-predators with an average number of links; (3) open diamond: either producers or top-predators with a single link; (4) full square: intermedier species with few links (let "few" mean $D \leq 3$ ); and (5) open triangle: intermedier species with many links (let "many" mean $D>3$ ). Based only on topology, the predictive power of these estimations are still in question. Nevertheless, considering how many types of indirect effects are implicitly given in a food web graph, it is supposed that these structural indices are worth, at least, for a rough inquiry.

\section{Discussion}

Based on topology, the network perspective helps in placing pairwise interactions into the context of whole trophic networks. This way, it is possible to estimate the strength of indirect effects, either locally (comparing species within a network) or globally (comparing average values of communities). Of course, factors other than topological also influence direct and indirect control on population dynamics. Thus, the relationship of direct and indirect effects between lynx and rabbit is not yet predict-

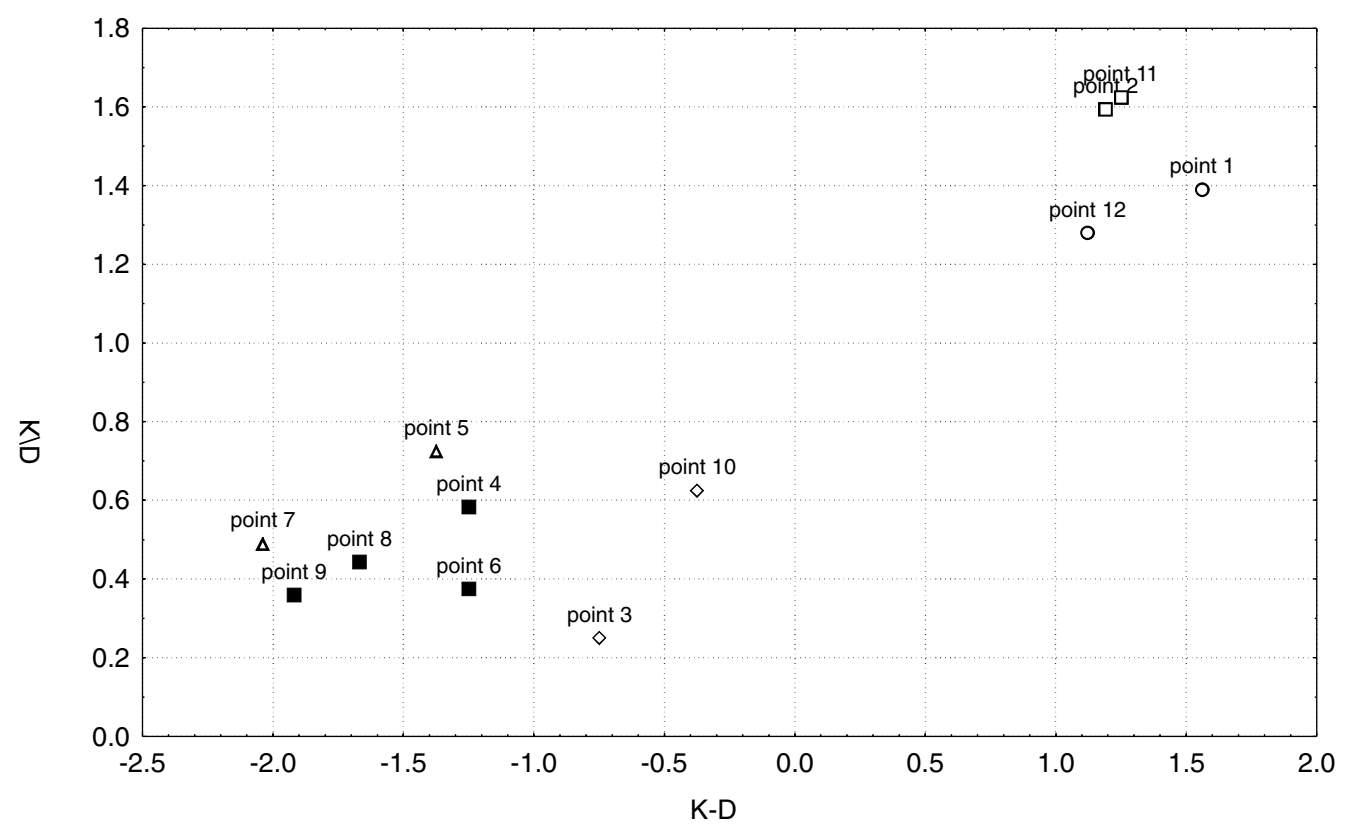

Figure 3. The indirect control ability of species (referred to as "points"), based on topology, is shown on the plane defined by $K-D$ and $K / D$. Indirect control is stronger if $K-D$ and $K / D$ are larger. Their combinations define domains of indirect control abilities. 
able at all but a possibly helpful quantitative approach has been suggested.

Acknowledgements: I thank Tamás Czárán for inspiring discussion on earlier work and two anonymous reviewers for their comments on the manuscript. This work was partly funded by OTKA F 029800

\section{References}

Abrams, P.A. 1983. Arguments in favour of higher order interactions. Am. Nat. 121:887-891.

Abrams, P. and H. Matsuda. 1993. Effects of adaptive predatory and anti-predator behaviour in a two-prey-one-predator system. Evol. Ecol. 7:312-326

Abrams, P.A., B.A. Menge, G.G. Mittelbach, D.A. Spiller, and P. Yodzis. 1996. The role of indirect effects in food webs. In: G.A. Polis and K.O. Winemiller (eds.), Food Webs: Integration of Patterns and Dynamics. Chapman and Hall, London. pp. 371395.

Billick, I. and T.J. Case. 1994. Higher order interactions in ecological communities: what are they and how can they be detected? Ecology 75:1529-1543.

Cohen, J.E. 1978. Food Webs and Niche Space. Princeton University Press, Princeton.

Hairston, N.G., F.E. Smith, and L.B. Slobodkin. 1960. Community structure, population control, and competition. Am. Nat. 94:421425.

Harary, F. 1961. Who eats whom? Gen. Syst. 6:41-44.

Higashi, M. and T.P. Burns (eds.). 1991. Theoretical Studies of Ecosystems - the Network Perspective. Cambridge University Press, Cambridge.

Jordán, F. 2000. Is the role of trophic control larger in a stressed ecosystem? Community Ecol. 1:139-146.

Jordán, F., A. Takács-Sánta, and I. Molnár. 1999. A reliability theoretical quest for keystones. Oikos 86:453-462.

Kareiva, P. 1994. Higher order interactions as a foil to reductionist ecology. Ecology 75:1527-1528.
Margalef, R. 1968. Perspectives in Ecological Theory. University of Chicago Press, Chicago, pp. 9-11.

Menge, B.A. 1995. Indirect effects in marine rocky intertidal interaction webs: patterns and importance. Ecol. Monogr. 65:21-74.

Menge, B.A. 1997. Detection of direct versus indirect effects: were experiments long enough? Am. Nat. 149:801-823.

Menge, B.A. and J.P. Sutherland. 1976. Species diversity gradients: synthesis of the roles of predation, competition, and temporal heterogeneity. Am. Nat. 110:351-369.

Morin, P.J. 1999. Community Ecology. Blackwell, Oxford.

Morin, P.J., S.P. Lawler, and E.A. Johnson. 1988. Competition between aquatic insects and vertebrates: interaction strength and higher order interactions. Ecology 69:1401-1409.

Paine, R.T. 1980. Food webs: linkage, interaction strength, and community infrastructure. J. Anim. Ecol. 49:667-685.

Palomares, F., P. Gaona, P. Ferreras, and M. Delibes. 1995. Positive effects on game species of top predators by controlling smaller predator populations: an example with lynx, mongooses, and rabbits. Cons. Biol. 9:295-305.

Pimm, S.L. 1980. Food web design and the effect of species deletion. Oikos 35:139-149.

Pimm, S.L. 1982. Food Webs. Chapman and Hall, London.

Power, M.E., M.S. Parker and J.T. Wootton. 1996. Disturbance and food chain length in rivers. In: G.A. Polis and K.O. Winemiller (eds.), Food Webs: Inte gration of Patterns and Dynamics. Chapman and Hall, London. pp. 286-297.

Schoener, T.W. 1983. Field experiments on interspecific competition. Am. Nat. 122:240-285.

Ulanowicz, R.E. and C.J. Puccia. 1990. Mixed trophic impacts in ecosystems. Coenoses 5:7-16.

Wootton, J.T. 1994a Predicting direct and indirect effects: an integrated approach using experiments and path analysis. Ecology 75:151-165.

Wootton, J.T. 1994b Putting the pieces together: testing the independence of interactions among organisms. Ecology 75:15441551 . 